\title{
Effect of tomato juice supplements consumption on the lipid profile of dyslipidemia patients
}

\author{
*Sugini \\ Nutrition Installation of Kendal District General Hospital, Central Java Province, Indonesia
}

\author{
Article history: \\ Received: 29 December 2019 \\ Received in revised form: 20 \\ April 2020 \\ Accepted: 24 May 2020 \\ Available Online: 30 May \\ 2020
}

Keywords:

Diet,

Tomato juice supplements,

Lipid profile,

Cardiovascular disease

DOI:

https://doi.org/10.26656/fr.2017.4(S3).S03

\begin{abstract}
The objective of this study was to determine the effect of tomato juice supplements consumption on the lipid profile of women with dyslipidemia patients. The design of this study was a quasi-control experimental design with pre-post test. The subjects were sixtytwo Kendal Hospital women employees, aged 35-50 years old, suffering from dyslipidemia but did not suffer from metabolic or degenerative diseases based on the examination of a specialist in internal medicine. Subjects were divided into two groups, group I (30 people) were given antioxidant supplements (336 g of tomatoes per day) for 21 days and group II ( 32 people) as control. The nutrition intake data was measured by the 24-hour food withdrawal method conducted for three consecutive days in three weeks of research calculated by the Nutrisurvey program. Data was analyzed with Kolmogorov Smirnov test, Pearson test and Mann Whitney test. There were significant relationships between energy intake, protein intake, fat intake, and carbohydrate intake with total cholesterol levels and triglyceride levels and there were also significant relationships between energy intake and fat intake with low density lipoprotein levels. It shows that there is a relationship between diet and dyslipidemia. There were significant differences in total cholesterol, low lipoprotein levels and triglycerides in treatment and control groups. This showed that tomato juice supplements significantly affect the lipid profiles.
\end{abstract}

\section{Introduction}

The relationship between blood cholesterol and heart disease has been well-established, with a decrease in Cholesterol Low Density Lipoprotein (LDL) being the main target of preventive therapy. High levels of LDL cholesterol in blood vessels cause these molecules to penetrate the sub-endothelial space which can be easily oxidized by free radicals. This oxidized LDL causes damage to nearby structures, causing the recruitment of monocytes to eliminate the oxidized LDL. This elimination process produces by-products in the form of foam cells. These foam cells release toxins that cause damage to endothelium cells, hypertrophy, and smooth muscle hyperplasia of blood vessels. This process also stimulates platelet aggregation which can interfere with the production or availability of nitric oxide which results in decreased blood vessel lumen and ischemia in tissues and organs. As this inflammatory process develops, high LDL cholesterol levels can develop into atherosclerosis (Fernandes et al., 2011).

Cardiovascular disease (CVD) is a leading cause of human disability and premature death worldwide. Diet has a direct relationship with the development of CVD and dietary changes are the current approach CVD prevention which is to increase consumption of fruits and vegetables as a good source of some antioxidant phytochemicals, e.g. carotenoids. Lycopene is the most abundant carotenoid in tomatoes and tomato products have gained profuse attention in recent years for their beneficial of health role, especially those related to their antioxidant effects and its protective role against CVD (Towhid and Marjia, 2017). Dietary and antioxidant supplements are efforts to prevent the development of dyslipidemia into cardiovascular disease. The 2015 US Diet Guidelines Advisory Committee summarizes the evidence for the benefits of a healthy diet on cardiometabolic outcomes and other diseases and also describes a healthy vegetarian diet, which includes more peas, soy products, nuts and seeds, and seeds. whole grains but does not include meat, poultry, or seafood (US Department of Agriculture and US Department of Health and Human Services, 2015). Women in the top aMed quintile have a lower risk for both Coronary Heart Disease (CHD) and stroke than bottom quintile $(\mathrm{RR}=$ $0.71(95 \% \mathrm{CI}=0.62-0.82$; $\mathrm{p}$ trend $<0.0001)$ for $\mathrm{CHD}$; RR 
$=0.87(95 \% \mathrm{CI}=0.73-1.02 ; \mathrm{p}$ trend $=0.03)$ for stroke $)$. CVD mortality was significantly lower among women in the top quintile of the aMed $(\mathrm{RR}=0.61,95 \% \mathrm{CI}=0.49$ 0.76, p trend $<0.0001$ ) (Fung, 2009). Lycopene may improve vascular function and contributes to the primary and secondary prevention of cardiovascular disorders. The main activity profile of lycopene includes antiatherosclerotic, antioxidant, anti-inflammatory, antihypertensive, antiplatelet, antiapoptotic, and protective endothelial effects, the ability to improve the metabolic profile, and reduce arterial stiffness. In this context, lycopene has been shown in many studies to exert a favorable effect in patients with subclinical atherosclerosis, metabolic syndrome, hypertension, peripheral vascular disease, stroke and several other cardiovascular disorders, although the results obtained are sometimes inconsistent, which warrants further studies focusing on its bioactivity (Loana et al., 2018). There was a study with randomised 36 statin treated CVD patients and 36 healthy volunteers in a 2:1 treatment allocation ratio to either $7 \mathrm{mg}$ lycopene or placebo daily for 2 months in a double-blind trial. Posttherapy EDV responses for lycopene-treated CVD patients were similar to $\mathrm{HVs}$ at baseline (2\% lower, $95 \%$ CI: $-30 \%$ to $+30 \%, \mathrm{P}=0.85$ ), also suggesting lycopene improved endothelial function. Lycopene supplementation improves endothelial function in CVD patients on optimal secondary prevention, but not in HVs (Gajendragadkar et al., 2014). Lycopene is found in many fruits and vegetables, there is a unique situation that more than $85 \%$ of the most dominant source of lycopene in human food comes from tomatoes (Solanum Lycopersicum esculentum Mill) and products made from tomatoes such as tomato paste, tomato sauce and tomato juice. The level of lycopene content in some tomato products varies from $8.8 \mu \mathrm{g} / \mathrm{g}$ in fresh tomatoes to 1200 $\mu \mathrm{g} / \mathrm{g}$ in tomato powder. The concentration of lycopene in tomatoes varies depending on the type of tomato, season, level of maturity. The concentration of lycopene in ripe tomato juice ranges from $8,600-9,300 \mu \mathrm{g} / 100 \mathrm{~g}$ or three times higher than fresh tomatoes (Voutilainen et al., 2006). The study was conducted using $336 \mathrm{~g}$ tomato juice $(350 \mathrm{~mL})$ equivalent to $30 \mathrm{mg}$ of lycopene with the same research time with a similar study in humans that is 3 weeks. The use of a dose of $30 \mathrm{mg} /$ day based on analysis from previous studies. Studies with lycopene dose of $20 \mathrm{mg} /$ day can significantly reduce total cholesterol, but not significantly in high density lipoprotein (HDL) and triglyceride (TG) (Collins et al., 2004), where studies with a lycopene dose $40 \mathrm{~m} /$ day show a positive correlation with total cholesterol, LDL, TG and HDL/LDL ratio, but negatively correlated with HDL (Haryanti, 2006).

This study was conducted at the Regional General
Hospital Dr. H. Soewondo Kendal, because cases of dyslipidemia in employees increased significantly, in 2009 there were 67 cases and increased to 108 cases in 2012. Cases of dyslipidemia include hypercholesterolemia, hypertriglyceride, a combination of both, with Diabetes Mellitus and with other diseases. The objective of this study was to determine the effects of tomato juice supplement consumption on the lipid profile of dyslipidemic patients.

\section{Materials and methods}

The design of this study was a quasi-control experimental design with pre-post test. Subjects were sixty-two Kendal Hospital women employees, aged 3550 years old, suffering from dyslipidemia but did not suffer from metabolic or degenerative diseases based on the examination of a specialist in internal medicine. Nutrition intake data was measured by 24 -hour food recall method for three days in three weeks of the study. Nutritional values were analyzed using the Nutrisurvey program. Food withdrawal is carried out using a food withdrawal form through interviews conducted by nutritionists. Subjects were divided into two groups; group I as the treatment group (30 people) were given with antioxidant supplements (336 g of tomatoes per day) for 21 days and group II (32 people) as the control group. Data on total cholesterol levels, LDL cholesterol levels, HDL cholesterol levels, and triglyceride levels were measured using the chemical analysis system of vitros 300 system by clinical pathology laboratory officers of Regional Hospital Dr. H. Soewondo Kendal, accredited by the government. Measurements were taken before and after supplementation. Blood was taken at 08.00 - 11.00 Western Indonesian Time (WIT) and immediately checked the total cholesterol level, LDL cholesterol level, HDL cholesterol level, and triglyceride level. Data was analyzed with Kolmogorov Smirnov test, Pearson test and Mann Whitney test. This research has been legalized by the Health Research Ethics Commission (KEPK) Faculty of Medicine, UNDIP and RSUP DR. Kariadi Semarang, with the issuance of "ETHICAL CLEARANCE" No. 329/EC/FKRSDK/2014.

\section{Results}

In Table 1, the results showed that the profile of the study subjects did not show differences in age, BMI, cholesterol intake, Mono Unsaturated Fatty Acid (MUFA) intake, Poly Unsaturated Fatty Acid (PUFA) intake, carbohydrate intake, fiber intake, vitamin A intake, and vitamin $\mathrm{C} \quad(\mathrm{p}>0.05)$. But there were differences in the percentage of energy intake and percentage fat intake $(p<0.05)$. 
Table 1. Characteristics of research subjects

\begin{tabular}{lccc}
\hline \multirow{2}{*}{ Variable } & Control Group $(\mathrm{n}=32)$ & Treatment Group $(\mathrm{n}=30)$ & \\
\cline { 2 - 3 } & Mean \pm SD & Mean \pm SD & \\
\hline age $($ years old & $45.2 \pm 3.4$ & $46.3 \pm 3.9$ & $0.05^{\mathrm{a}}$ \\
BMI $\left(\mathrm{kg} / \mathrm{m}^{2}\right)$ & $27 \pm 2.1$ & $27.3 \pm 3.1$ & $0.96^{\mathrm{b}}$ \\
Energy intake (\% REE) & $124 \pm 14.4$ & $116.5 \pm 13$ & $0.04^{\mathrm{b}}$ \\
Fat intake (\% E) & $36 \pm 1.7$ & $35 \pm 2.7$ & $0.04^{\mathrm{b}}$ \\
Carbohidrate intake (\% E) & $51 \pm 1.6$ & $50.5 \pm 3.8$ & $0.30^{\mathrm{b}}$ \\
fiber intake (g) & $23.4 \pm 2.4$ & $22.8 \pm 2.9$ & $0.22^{\mathrm{b}}$ \\
Cholesterol intake (g) & $191.2 \pm 27.8$ & $199.3 \pm 42.4$ & $0.27^{\mathrm{b}}$ \\
MUFA intake (g) & $24.6 \pm 2.7$ & $23.6 \pm 2.9$ & $0.24^{\mathrm{b}}$ \\
PUFA intake (g) & $33.4 \pm 3.9$ & $31.5 \pm 3.6$ & $0.07^{\mathrm{b}}$ \\
Vitamin A intake ( $\mu \mathrm{gg})$ & $1465.6 \pm 295.6$ & $1472.6 \pm 260.8$ & $0.49^{\mathrm{b}}$ \\
Vitamin C intake $(\mathrm{mg})$ & $123.4 \pm 6.8$ & $124.3 \pm 9.1$ & $0.75^{\mathrm{b}}$ \\
\hline \multicolumn{2}{c}{${ }^{\mathrm{a}}$ Mann Whitney, ${ }^{\mathrm{b}}$ Independent Samples t-test } & &
\end{tabular}

In Table 2 significant relationships between energy intake $(\mathrm{P}=0.001, \mathrm{r}=0.501)$, fat intake $(\mathrm{P}=0.001, \mathrm{r}=$ $0.574)$, protein intake $(\mathrm{P}=0.008, \mathrm{r}=335)$ and carbohydrate intake $(\mathrm{P}=0.001, \mathrm{r}=0.446)$ with total cholesterol levels were observed. There was also a significant relationship between the fat intake $(\mathrm{P}=0.012$, $\mathrm{r}=0.318$ ) with LDL levels and there were significant relationships between energy intake $(\mathrm{P}=0.005, \mathrm{r}=353)$, fat intake $(\mathrm{P}=0.008, \mathrm{r}=336)$, protein intake $(\mathrm{P}=0.016$, $\mathrm{r}=305)$, and carbohydrate intake $(\mathrm{P}=0.013 \mathrm{r}=315)$ with triglyceride levels.

Table 3 shows the lipid profile of the study subjects before the study. There were no differences between the treatment group and the control group in the total cholesterol levels and the LDL levels $(\mathrm{p} \geq 0.05)$ but, there were differences in the HDL levels and the triglyceride levels $(\mathrm{p}<0.05)$.

The lipid profile of the subjects after the study can be seen in Table 4.There is a difference between the total cholesterol and the LDL levels $(p<0.05)$ between the treatment group and the control group but no difference in the HDL levels and the triglyceride levels $(p \geq 0.05)$.

The treatment results can seen in Table 5, there were significant differences in total cholesterol $(p=0.001)$, low lipoprotein $(\mathrm{p}=0.001)$ and triglyceride levels $(\mathrm{p}=$ 0.010 ) in the treatment and the control groups. This shows that there is a significant relationship between the

Table 2. Relationship between food intake and research subject profiles

\begin{tabular}{lccc}
\hline \multicolumn{1}{c}{ Variable } & Total Cholesterol Level & LDL Level & TG Level \\
\hline Energy intake & $\mathrm{P}=0.001, \mathrm{r}=0.501$ & $\mathrm{P}=0.110, \mathrm{r}=205$ & $\mathrm{P}=0.005, \mathrm{r}=353$ \\
Fat intake & $\mathrm{P}=0.001, \mathrm{r}=0.574$ & $\mathrm{P}=0.012, \mathrm{r}=0.318$ & $\mathrm{P}=0.008, \mathrm{r}=336$ \\
Protein intake & $\mathrm{P}=0.008, \mathrm{r}=335$ & $\mathrm{P}=0.449, \mathrm{r}=0.098$ & $\mathrm{P}=0.016, \mathrm{r}=305$ \\
Carbohidrate intake & $\mathrm{P}=0.001, \mathrm{r}=0.446$ & $\mathrm{P}=0.325, \mathrm{r}=0.127$ & $\mathrm{P}=0.013, \mathrm{r}=315$ \\
\hline
\end{tabular}

Table 3. Lipid profile of subjects before in the treatment group and control group

\begin{tabular}{lccc}
\hline \multicolumn{1}{c}{ Variable } & Control Group $(\mathrm{n}=32)$ & Treatment Group $(\mathrm{n}=30)$ & \\
& Mean \pm SD & Mean \pm SD & -value \\
\hline Total cholesterol pre $(\mathrm{g} / \mathrm{dL})$ & $225.9 \pm 19.3$ & $231.7 \pm 24.7$ & $0.45^{\mathrm{a}}$ \\
HDL pre $(\mathrm{g} / \mathrm{dL})$ & $53.8 \pm 9.6$ & $48.7 \pm 11.3$ & $0.04^{\mathrm{b}}$ \\
LDL pre $(\mathrm{g} / \mathrm{dL})$ & $144.9 \pm 29.2$ & $150.7 \pm 23.3$ & $0.22^{\mathrm{b}}$ \\
TG pre $(\mathrm{g} / \mathrm{dL})$ & $148.9 \pm 69.7$ & $189.4 \pm 79.2$ & $0.01^{\mathrm{a}}$ \\
\hline
\end{tabular}

${ }^{\mathrm{a}}$ Mann Whitney, ${ }^{\mathrm{b}}$ Independent Samples t-test

Table 4. Lipid profile of subjects after in the treatment group and control group

\begin{tabular}{lccc}
\hline \multicolumn{1}{c}{ Variable } & Control Group $(\mathrm{n}=32)$ & Treatment Group $(\mathrm{n}=30)$ & p-value \\
& Mean \pm SD & Mean \pm SD & p-vol \\
\hline Total cholesterol post $(\mathrm{g} / \mathrm{dL})$ & $231.3 \pm 24.5$ & $202.1 \pm 23.7$ & $0.00^{\mathrm{a}}$ \\
HDL post $(\mathrm{g} / \mathrm{dL})$ & $54.9 \pm 7.5$ & $53.1 \pm 9.7$ & $0.23^{\mathrm{b}}$ \\
LDL post $(\mathrm{g} / \mathrm{dL})$ & $144.8 \pm 23.5$ & $117.5 \pm 23.05$ & $0.00^{\mathrm{b}}$ \\
TG post $(\mathrm{g} / \mathrm{dL})$ & $156.9 \pm 49.73$ & $148.2 \pm 56.05$ & $0.55^{\mathrm{a}}$ \\
\hline
\end{tabular}

${ }^{\mathrm{a}}$ Mann Whitney, ${ }^{\mathrm{b}}$ Independent Samples t-test 
Table 5. Changes in the lipid profile of the treatment and control group

\begin{tabular}{lccc}
\hline \multicolumn{1}{c}{ Variable } & $\begin{array}{c}\text { Control Group }(\mathrm{n}=32) \\
\text { Mean } \pm \text { SD }\end{array}$ & $\begin{array}{c}\text { Treatment Group }(\mathrm{n}=30) \\
\text { Mean } \pm \text { SD }\end{array}$ & p-value \\
\hline Total cholesterol (g/dL) & $-29.6 \pm 15.2$ & $5.3 \pm 12.3$ & $0.001^{\mathrm{a}}$ \\
d-HDL (g/dL) & $4.4 \pm 8.9$ & $0.83 \pm 4.3$ & $0.070^{\mathrm{b}}$ \\
d-LDL (g/dL) & $-32.5 \pm 21.8$ & $-0.8 \pm 20.1$ & $0.001^{\mathrm{b}}$ \\
d-triglyceride (g/dL) & $-41.2 \pm 67.3$ & $8 \pm 40.9$ & $0.010^{\mathrm{a}}$ \\
\hline
\end{tabular}

${ }^{\mathrm{a}}$ Mann Whitney, ${ }^{\mathrm{b}}$ Independent Samples t-test, negative symbol indicates decreasing value

tomato juice supplementation and lipid profile.

\section{Discussion}

The average age of the subjects is 46 years, including middle-aged adults who are at risk of fat tissue with decreased metabolism. The older a person is, the ability of LDL receptors is reduced, causing blood LDL to increase. About $9 \%$ of subjects' BMI were obese or an average of $27 \mathrm{~kg} / \mathrm{m}^{2}$. Obese adults were more at risk than normal weight adults as they have high total cholesterol, LDL and triglyceride levels which is a major risk factor for coronary heart disease. Obesity, especially central obesity, carries a greater risk for coronary heart disease and other degenerative diseases and dyslipidemia. Excess Very Low Density Lipoprotein (VLDL) is produced in the liver in obese people and subsequently the VLDL is converted to LDL (Nelms et al., 2010). Due to that, the lipid and lipoprotein profiles of obese people are changed with increasing triglycerides and decreasing HDL (Hansen et al., 2005).

Most of the subjects (90.3\%) have high energy intake at the average of $2300 \mathrm{kcal}$. High energy intake results in fat accumulation, especially triglycerides. This will increase VLDL and LDL in blood which will cause an increase in total cholesterol. The fat intake of the study subjects exceeded the nutritional adequacy rate (25 $-30 \%$ ) i.e. the average was $34.49 \%$ in the treatment group and $35.66 \%$ in the control group. When a person consumes more fatty food, fat and triglyceride levels in the body will increase. This will increase blood VLDL and LDL (Murray et al., 2009).

Significant relationships between energy intake $(\mathrm{P}=$ $0.001, r=0.501)$, fat intake $(P=0.001, r=0.574)$, protein intake $(\mathrm{P}=0.008, \mathrm{r}=335)$ and carbohydrate intake $(\mathrm{P}=0.001, \mathrm{r}=0.446)$ with total cholesterol levels were observed. There was a significant relationship between fat intake ( $\mathrm{P}=0.012, \mathrm{r}=0.318)$ with $\mathrm{LDL}$ levels. There were significant relationships between energy intake $(\mathrm{P}=0.005, \mathrm{r}=353)$, fat intake $(\mathrm{P}=0.008$, $\mathrm{r}=336)$, protein intake $(\mathrm{P}=0.016, \mathrm{r}=305)$ and carbohydrate intake $(\mathrm{P}=0.013 \mathrm{r}=315)$ with triglyceride levels, which is in line with this research. When compared with a higher-carbohydrate Dietary Approaches to Stop Hypertension (DASH) diet, DASH- type diet with higher protein lowered LDL by $3.3 \mathrm{mg} / \mathrm{dL}$, and triglycerides by $16 \mathrm{mg} / \mathrm{dL}$. Compared with a highercarbohydrate DASH diet, DASH-type diet with higher unsaturated fat lowered triglycerides by $10 \mathrm{mg} / \mathrm{dL}$ (Benjamin et al., 2019). In a meta-analysis of 60 randomized controlled feeding trials, consumption of $1 \%$ of calories lowered triglycerides (Jenkins et al., 2017).

In a meta-analysis of four prospective cohort studies involving nearly 140,000 subjects, including updated analyses from the two largest studies, a 2 percent increase in energy intake from trans fatty acids was associated with a 23 percent increase in the incidence of CHD (pooled relative risk, 1.23; 95 percent confidence interval, 1.11 to $1.37 ; \mathrm{P}<0.001$ ) (Mozaffarian et al., 2006).In meta-analyses of prospective cohort studies, greater consumption of refined complex carbohydrates, starches, and sugars, as assessed by glycemic index or load, was associated with significantly higher risk of CHD and DM. When the highest category (total sedentary time) was compared with the lowest category (short sedentary time), risk of CHD was 36\% greater (glycemic load: RR, 1.36; 95\% CI, 1.13-1.63) and risk of Diabetes Mellitus was $40 \%$ greater (glycemic index: RR, 1.40; 95\% CI, 1.23-1.59) (Qi et al., 2015; Diaz et al., 2017).

When the highest category was compared with the lowest category, dietary Linoleic Acid (LA) was associated with a $15 \%$ lower risk of CHD events (pooled $\mathrm{RR}, 0.85 ; 95 \%$ confidence intervals, $0.78-0.92 ; \mathrm{I}(2)=$ $35.5 \%$ ) and a $21 \%$ lower risk of CHD deaths (pooled $\mathrm{RR}, 0.79 ; 95 \%$ confidence intervals, 0.71-0.89; $\mathrm{I}(2)=$ $0.0 \%$ ). A $5 \%$ of energy increment in LA intake replacing energy from saturated fat intake was associated with a 9\% lower risk of CHD events (RR, 0.91; 95\% confidence intervals, $0.87-0.96$ ) and a $13 \%$ lower risk of CHD deaths (RR, 0.87; 95\% confidence intervals, 0.820.94) (Farvid et al., 2014).

The association suggested that replacing SFA with PUFA rather than MUFA or carbohydrates prevents CHD through various intakes. In comparison, in an analysis of individual levels collected from 11 prospective cohort studies, the specific exchange of PUFA consumption at SFA sites was associated with a lower risk of CHD, with a $13 \%$ lower risk for each $5 \%$ 
energy exchange (RR, 0.87; $95 \%$ CI, $0.70-0.97$ (Jakobsen et al., 2009).

These findings provided evidence that consuming PUFA as a substitute for SFA reduces the incidence of CHD in RCTs. This also showed that instead of trying to reduce PUFA consumption, a shift towards a larger PUFA population as a substitute for SFA will significantly reduce the level of CHD (Mozaffarian et al., 2010).

The replacement of animal fats, including dairy fat, with vegetable sources of fats and PUFAs may reduce risk of CVD. whereas the 5\% energy intake substitution of other animal fat with dairy fat was associated with $6 \%$ increased CVD risk (RR: 1.06; 95\% CI: 1.02, 1.09) (Chen et al., 1016).

There were significant differences in total cholesterol $(\mathrm{p}=0.001)$, low lipoprotein $(\mathrm{p}=0.001)$ and triglyceride levels $(p=0.010)$ in the treatment and control groups. This shows that supplementation of 336 $\mathrm{g}(350 \mathrm{~mL})$ tomato juice per day for 21 days in women with dyslipidemia with minimal risk can reduce total cholesterol levels by $29.6 \mathrm{~g} / \mathrm{dL}$, LDL levels by $32.5 \mathrm{~g} /$ $\mathrm{dL}$, triglyceride levels by $41.4 \mathrm{~g} / \mathrm{dL}$.

The results of this study are in line with research by Mozaffarian et al. (2010) which states that these findings are consistent with a meta-analysis of RCTs in which increased PUFA consumption in place of SFAs reduced CHD events, with $10 \%$ lower risk for each $5 \%$ energy exchange (RR, 0.90; 95\% CI, 0.83-0.97.

Among Chinese adults, a higher level of fruit consumption is associated with a lower risk of major cardiovascular disease (Du et al., 2016). Several studies have examined the relationship between antioxidant intake and lipid peroxidation to try to determine which antioxidants play a role in preventing cardiovascular disease. The hydrocarbon carotenoids, including $\beta$ carotene and lycopene, are transported primarily in LDL, which puts them in prime position to protect LDL from oxidation (Fung et al., 2009).

Lycopene may have a cholesterol synthesisinhibiting effect and may enhance LDL degradation. Available evidence suggests that intimal wall thickness and risk of myocardial infarction are reduced in persons with higher adipose tissue concentrations of lycopene (Lenore and Susan, 2000).

Treatment with lycopene increased the ejection fraction (EF) from $45.2 \pm 3.12$ to $51.1 \pm 4.63$, and it decreased the left ventricular at end-diastole diameter (LVEDd) from $6.52 \pm 0.37 \mathrm{~mm}$ to $6.18 \pm 0.41 \mathrm{~mm}$ and the left ventricular at end-systole diameter (LVESd) from
$4.29 \pm 0.63$ to $3.94 \pm 0.37$ at 28 days post-myocardial infarction. Lycopene attenuated the MI-induced increase in MMP-9 and type I collagen expression, and inhibited p38 activation. Moreover, lycopene decreased the collagen volume fraction in the peri-infarcted zone. The data indicated that lycopene improved the cardiac function and ventricular remodeling by inhibiting p38 activation and MMP-9 expression (Wang et al., 2014). Lycopene can suppress VSMCs proliferation, due to inhibiting G1 phase cells entry into the S phase of the cell cycle, related to its antioxidative effect (Kimet al., 2010), and synthesis of oxidized LDL may be impaired by lycopene (Kimet al., 2011). Loana et al. (2018) reviewed the importance of lycopene in improving vascular function and in the primary and secondary prevention of cardiovascular disorders. The effects shown by lycopene in view of cardiovascular health consist of general antioxidants and anti-inflammatory, antiplatelet, anti-apoptotic and antihypertensive properties, ability to improve endothelial function, metabolic profile and ventricular remodeling, reduction in arterial stiffness as well as reduction in atherosclerotic plaque size. Lycopene exerts favorable effects in patients with subclinical atherosclerosis, metabolic syndrome, hypertension, peripheral vascular disease, and several other cardiovascular disorders, but sometimes conflicting results were obtained. Clearly, more and better-designed studies will be necessary to improve our understanding of the positive effects of lycopene on vascular health and to elucidate the involved mechanisms on a molecular level. Future cardiovascular disease prevention strategies might include lycopene-enriched products, lycopene supplementation and new combinations including lycopene. Future studies should be focused on dietary lycopene and its synergistic effects with other dietary components in different study populations, with elevated cardiovascular risk, are highly warranted which might enable development of functional foods useful in prevention and complementary treatment of cardiovascular disorders (Fung et al., 2009).

\section{Conclusion}

There is a significant relationship between energy intake, fat intake, protein intake and carbohydrate intake with total cholesterol levels. So, there is a significant relationship between fat intake with LDL levels and there is a significant relationship between energy intake, fat intake, protein intake and carbohydrate intake with triglyceride levels. About $53.3 \%$ of the treatment group subjects had total cholesterol levels normal $(<200 \mathrm{mg} /$ dL) after the study and $20 \%$ of the treatment group subjects had their LDL levels normal $(<100 \mathrm{mg} / \mathrm{dL})$ after the study. Supplementation of $336 \mathrm{~g}(350 \mathrm{~mL})$ tomato juice per day for 21 days in women with dyslipidemia 
with minimal risk can reduce total cholesterol levels by $29.6 \mathrm{~g} / \mathrm{dL}$, LDL levels by $32.5 \mathrm{~g} / \mathrm{dL}$, and triglyceride levels by $41.4 \mathrm{~g} / \mathrm{dL}$.

\section{References}

Benjamin, E.J., Muntner, P., Alonso, A., Bittencourt, M.S., Callaway, C.W., Carson, A.P., Chamberlain, A.M., Chang, A.R., Cheng, S., Das, S.R., Delling, F.N., Djousse, L., Elkind, M.S.V., Ferguson, J.F., Fornage, M., Jordan, L.C., Khan, S.S., Kissela, B.M., Knutson, K.L., Kwan, T.W., Lackland, D.T., Lewis, T.T., Lichtman, J.H., Longenecker, C.T., Loop, M.S., Lutsey, P.L., Martin, S.S., Matsushita, K., Moran, A.E., Mussolino, M.E., O'Flaherty, M., Pandey, A., Perak, A.M., Rosamond, W.D., Roth, G.A., Sampson, U.K.A., Satou, G.M., Schroeder, E.B., Shah, S.H., Spartano, N.L., Stokes, A., Tirschwell, D.L., Tsao, C.W., Turakhia, M.P., VanWagner, L.B., Wilkins, J.T., Wong, S.S. and Virani, S.S. (2019). Heart Disease and Stroke Statistics-2019 Update. A Report From the American Heart Association. Circulation, 139(10), e56-e528. https://doi.org/10.1161/ CIR.0000000000000659

Chen, M., Li, Y., Sun, Q., Pan, A., Manson, J.E., Rexrode, K.M., Willett, W.C., Rimm, E.B. and Hu, F.B. (2016). Dairy fat and risk of cardiovascular disease in 3 cohorts of US adults. American Journal of Clinical Nutrition, 104(5),1209-1217. https:// doi.org/10.3945/ajen.116.134460

Collins, J.K., Arjmandi, H.H., Claypool, P.L., PerkinsVeazie, P., Baker, R.A. and Clevidence, B.A. (2004). Lycopene From Two Food Sources Does not Affect Antioxidant or Cholesterol Status of Middle-Aged Adult. Nutrition Journal, 3, 15. https:// doi.org/10.1186/1475-2891-3-15

Diaz, K.M., Goldsmith, J., Greenlee, H., Strizich, G., Qi, Q., Mossavar-Rahmani, Y., Vidot, D.C., Buelna, C., Brintz, C.E., Elfassy, T., Gallo, L.C., Daviglus, M.L., Sotres-Alvarez, D. and Kaplan, R.C. (2017). Prolonged, uninterrupted sedentary behavior and glycemic biomarkers among US Hispanic/Latino adults: the HCHS/SOL (Hispanic Community Health Study/Study of Latinos). Circulation, 136, 13621373. https://doi.org/10.1161/ CIRCULATIONAHA.116.026858

Du, H., Li, L., Bennett, D., Guo, Y., Key, T.J., Bian, Z., Sherliker, P., Gao, H., Chen, Y., Yang, L., Chen, J., Wang, S., Du, R., Su, H., Collins, R., Peto, R. and Chen, Z. (2016). Fresh Fruit Consumption and Major Cardiovascular Disease in China China Kadoorie Biobank Study. New England Journal of Medicine, 374(14), 1332-1343. https://doi.org/10.1056/

\section{NEJMoa1501451}

Farvid, M.S., Ding, M., Pan, A., Sun, Q., Chiuve, S.E., Steffen, L.M., Willett, W.C. and Hu, F.B. (2014). Dietary linoleic acid and risk of coronary heart disease: a systematic review and meta-analysis of prospective cohort studies. Circulation, 130, 1568$1578 . \quad$ https://doi.org/10.1161/ CIRCULATIONAHA.114.010236

Fernandes, R.A., Christofaro, D.G., Casonatto, J., Codogno, J.S., Rodrigues, E.Q., Cardoso, M.L., Kawaguti, S.S. and Zanesco, A. (2011). Prevalence of Dyslipidemia in Individuals Physically Active during Childhood, Adolescence and Adult Age. Arquivos Brasileiros de Cardiologia, 97(4), 317323. https://doi.org/10.1590/S0066782X2011005000083

Fung, T.T., Rexrode, K.M., Mantzoros, C.S., Manson, J.A.E., Willett, W.C. and Hu, F.B. (2009). Mediterranean diet and incidence of and mortality from coronary heart disease and stroke in women [published correction appears in Circulation. 2009;119:e379] Circulation, 119, 1093-1100. https://doi.org/10.1161/

CIRCULATIONAHA.108.816736

Hansen, A.S., Marckmann, P., Dragsted, L.O., Finné Nielsen, I.L., Nielsen, S.E. and Grønbaek, M. (2005). Effect of Red Wine and Red Grape Extract on Blood Lipids, Haemostatic Factor and Other Risk Factors for Cardiovascular Disease. European Journal of Clinical Nutrition, 59, 449-455. https:// doi.org/10.1038/sj.ejen.1602107

Haryanti, E.H.W. (2006). Effects of Lycopene Giving on Lipid and Lipid Profile of Hypercholesterolemia Serum Rats Serum Lipids. Indonesia: Diponegoro University Library. Thesis

Jakobsen, M.U., O'Reilly, E.J., Heitmann, B.L., Pereira, M.A., Bälter, K., Fraser, G.E., Goldbourt, U., Hallmans, G., Knekt, P., Liu, S., Pietinen, P., Spiegelman, D., Stevens, J., Virtamo, J., Willett, W.C. and Ascherio, A. (2009). Major types of dietary fat and risk of coronary heart disease: a pooled analysis of 11 cohort studies. American Journal of Clinical Nutrition, 89(5), 1425-1432. https://doi.org/10.3945/ajcn.2008.27124

Jenkins, G.P., Evenson, K.R., Herring, A.H., Hales, D. and Stevens, J. (2017). Cardiometabolic correlates of physical activity and sedentary patterns in U.S. youth. Medicine and Science in Sports and Exercise, 49(9), 1826-1833. https://doi.org/10.1249/ MSS.0000000000001310

Kim, J.Y., Paik, J. K., Kim, O.Y., Park, H. W., Lee, J. H., Jang, Y. and Lee, J.H. (2011). Effects of lycopene supplementation on oxidative stress and 
markers of endothelial function in healthy men. Atherosclerosis, 215(1), 189-195. https:// doi.org/10.1016/j.atherosclerosis.2010.11.036

Kim, O.Y., Yoe, H.Y., Kim, H.J., Park, J.Y., Kim, J.Y., Lee, S.H., Lee, J.H., Lee, K.P., Jang, Y. and Lee, J.H. (2010). Independent inverse relationship between serum lycopene concentration and arterial stiffness. Atherosclerosis, 208(2), 581-586. https:// doi.org/10.1016/j.atherosclerosis.2009.08.009

Lenore, A. and Susan, S. (2000). Lycopene and cardiovascular disease. The American Journal of Clinical Nutrition, 71(6), 1691S- 1695S. https:// doi.org/10.1093/ajen/71.6.1691S

Loana, M., Dana, S., Alexandru, C., Clemens, M., Jarosław, O.H. and Atanasov, A.G. (2018). Lycopene and Vascular Health. Frontiers in Pharmacology, 9, 521. https://doi.org/10.3389/ fphar.2018.00521

Mozaffarian, D., Katan. M.B., Ascherio, A., Stampfer, M.J. and Willett, W.C. (2006). Trans Fatty Acids and Cardiovascular Disease. The New England Journal of Medicine, 354, 1601-13. https:// doi.org/10.1056/NEJMra054035

Mozaffarian, D., Micha, R. and Wallace, S. (2010). Effects on coronary heart disease of increasing polyunsaturated fat in place of saturated fat: a systematic review and meta-analysis of randomized controlled trials. PLoS Medicine, 7(3), e1000252. https://doi.org/10.1371/journal.pmed.1000252

Murray, R.K., Bernder, D.A., Botham, K.M., Kennelly, P.J., Rodwell, V.W. and Weil, P.A. (2009). Harper's Illustrated Biochemistry. $27^{\text {th }}$ ed. New York, USA: McGraw Hill

Nelms, M., Kathryn, P.S., Karen, L. and Sara, L.R. (2010). Nutrition Therapy and Pathophysiology. $2^{\text {nd }}$ ed. Boston, United States: Cengage Learning.

Gajendragadkar, P.R., Hubsch, A., Mäki-Petäjä, K.M., Serg, M., Wilkinson, I.B. and Cheriyan, J. (2014). Effects of Oral Lycopene Supplementation on Vascular Function in Patients with Cardiovascular Disease and Healthy Volunteers: A Randomised Controlled Trial. PlosOne, 9(6), e99070. https:// doi.org/10.1371/journal.pone.0099070

Qi, Q., Strizich, G., Merchant, G., Sotres-Alvarez, D., Buelna, C., Castañeda, S.F., Gallo, L.C., Cai, J., Gellman, M.D., Isasi, C.R., Moncrieft, A.E., Sanchez-Johnsen, L., Schneiderman, N. and Kaplan, R.C. (2015). Objectively measured sedentary time and cardiometabolic biomarkers in US Hispanic/ Latino adults: the Hispanic Community Health Study/Study of Latinos (HCHS/SOL). Circulation, 132, 1560-1569. https://doi.org/10.1161/

\section{CIRCULATIONAHA.115.016938}

Towhid, H. and Marjia, S. (2017). Lycopene and Cardiovascular Diseases: A Review of the Literature. International Journal of Research and Review, 4(1), 73-86.

US Department of Agriculture and US Department of Health and Human Services. (2015). Dietary Guidelines for Americans, 2015-2020. 8th ed. Washington, DC: US Government Printing Office.

Voutilainen, S., Nurmi, T., Mursu, J. and Rissanen, T.H. (2006). Carotenoids and Cardiovascular Health. American Journal of Clinical Nutrition, 83(6), 12651271. https://doi.org/10.1093/ajcn/83.6.1265

Wang, X., Lv, H., Gu, Y., Wang, X., Cao, H., Tang, Y., Chen, H. and Huang, C. (2014). Protective effect of lycopene on cardiac function and myocardial fibrosis after acute myocardial infarction in rats via the modulation of p38 and MMP-9. Journal of Molecular Histology, 45(1), 113-1120. https:// doi.org/10.1007/s10735-013-9535-2 